\title{
Elaboração de planos de aulas para educação física: a percepção discente
}

\author{
Lesson plans development for physical education: the students' perception \\ DOI: http://dx.doi.org/10.36453/2318-5104.2018.v16.n1.p185

\section{Fernanda Carvalho Bittencourt de Oliveira ${ }^{1}$, Maria Teresa Sudário Rocha ${ }^{2}$, Emerson Cruz de Oliveira ${ }^{1}$}

\author{
${ }^{1}$ Universidade Federal de Ouro Preto (UFOP) \\ ${ }^{2}$ Faculdade Presidente Antônio Carlos de Conselheiro Lafaiete (UNIPAC)
}

\section{RESUMO}

O plano de aula é extremamente importante para as atividades docentes, mas pouco se discute sobre os itens que o compõe, assim como os aspectos práticos de sua elaboração. $O$ foco da discussão centrava-se em fundamentos teóricos que também são imprescindíveis, mas que já foram bem discutidos. A reflexão pode ser ampliada, discutindo itens importantes para o registro e a sistematização da produção de conhecimentos na área da Educação Física, por meio dos planos de aulas. O objetivo do estudo foi comparar a percepção dos discentes iniciantes e concluintes de um curso de Licenciatura em Educação Física sobre a importância dos itens que compõem um plano de aula, bem como discutir esses itens considerando aspectos práticos da elaboração de um plano de aula. Trata-se de um estudo exploratório-descritivo, com uma amostra de 15 graduandos com possibilidade real de conclusão do curso (grupo concluintes) e 15 graduandos do primeiro e segundo períodos (grupo iniciantes), de ambos os sexos, que receberam uma lauda de papel pautado com a solicitação de montagem de um plano de aula com o conteúdo de sua escolha. Para análise dos planos de aula, os pesquisadores tinham à sua disposição uma lista de itens previamente elencados após estudo. Para análise estatística dos dados, utilizou-se o teste Qui-Quadrado, sendo adotado nível de significância de 5\%. A "descrição das atividades" foi o único item que todos aos alunos perceberam como importante e apresentaram em seus planos. O segundo item mais lembrado foi a definição de objetivos para aula. $\mathrm{O}$ contraponto foi a não apresentação de sugestão de "referências bibliográficas" e "espaço para comentários e reflexões após a aula". Muito ainda precisa ser discutido sobre os demais itens que compõem um plano de aula que não deveria se resumir a uma descrição das atividades propostas para aula.

PALAVRAS-CHAVE: Plano de aula; Educação Física; Escola.

\section{ABSTRACT}

The lesson plan is extremely important for teaching activities, but little is discussed about the items that compose it, as well as the practical aspects of its elaboration. The focus of the discussion centered on theoretical foundations that are also indispensable, but which have already been well discussed. The reflection can be broadened, discussing important items for the registration and systematization of the production of knowledge in the area of Physical Education, through the lesson plans. The aim of this study was to compare the perception of beginning and finishing students of a Licentiate degree in Physical Education on the importance of the items that make up a lesson plan, as well as discuss these items considering practical aspects of the elaboration of a lesson plan. This is an exploratory-descriptive study, with a sample of 15 graduates with a real possibility of completing the course (concluding group) and 15 graduates of the first and second periods (beginning group) of both sexes, who received a lined paper with the request to assemble a lesson plan with the content of their choice. For the analysis of the lesson plans, the researchers had at their disposal a list of items previously listed after study. For the statistical analysis of the data, the chi-square test was used, being adopted a level of significance of $5 \%$. The "description of activities" was the only item that all students perceived as important and presented in their plans. The second most remembered item was the setting of objectives for class. The counterpoint was the lack of suggestion of "bibliographical references" and "space for comments and reflections after class". Finally, much still needs to be discussed about the other items that make up a lesson plan that should not be limited to a description of the activities proposed for class.

KEYWORDS: Lesson plan; Physical Education; School. 


\section{INTRODUÇÃO}

A prática cotidiana do professor de educação física é permeada por dificuldades comumente encontradas na maioria das escolas, como o problema da falta de materiais disponíveis, a exposição às intempéries climáticas (ARRUDA, 2011), salários insuficientes, status social inferiorizado (UNESCO, 2004), excessivo número de alunos nas suas turmas, falta de tempo para planejar suas aulas (ALENCAR; FLEITH, 2008) e a inferioridade de sua disciplina frente às outras disciplinas da escola (NOGUEIRA, 2004).

Outra dificuldade é o acesso a um referencial teórico que venha a debater aspectos práticos sobre a elaboração de planos de aulas na educação física. Questões epistemológicas e metodológicas com destaque para o tipo de conhecimento que deve compor o conteúdo da Educação Física, assim como as formas desejáveis para transmitir esses conteúdos já foram bem discutidos (SOARES et al., 1992). Outras obras também se aprofundaram nas discussões teóricas e acabaram tornando-se referência para cada uma das chamadas abordagens da educação física, para um primeiro contato com essas discussões teóricas a obra de Darido (2003) apresenta uma boa síntese. No presente trabalho não se pretende discutir a importância ou valor de cada obra e de sua abordagem correspondente, mas sim iniciar uma reflexão a partir de perguntas simples.

Os professores de educação física estão preparados para construir seus planos de aula? Os discentes de cursos de licenciatura em educação física estão sendo preparados para essa importante tarefa? Qual o tempo dedicado à elaboração de planos de aulas na universidade e qual o tempo utilizado para discussões mais amplas sobre a pedagogia da educação física?

Obviamente nem todas essas questões serão respondidas em apenas um trabalho. Muito menos em um estudo que pretende se dedicar a questões práticas na elaboração de planos de aulas, por reconhecer também a falta de tempo disponível para a sua elaboração por parte do professor de Educação Física conforme já discutido em outro trabalho (ALENCAR; FLEITH, 2008).

Sabe-se que a imposição de jornadas duplas e a necessidade de atuar em duas ou três escolas não é privilégio do professor de Educação Física, mas para esse profissional a falta de um plano de aula acaba fazendo com que o professor seja comparado a um recreador (NASCIMENTO; SILVA; SANTOS, 2013).

Antes de discutir o plano de aula, é necessário pontuar outros aspectos que o precedem e que, se bem observados, culminam em um instrumento bem preparado. Assim, é necessário estudar antes aspectos do planejamento, que visa organizar o ambiente de trabalho do professor de maneira que o alcance dos objetivos seja facilitado. Cruz (1976) afirma que o planejamento é desenvolvido a fim de evitar improvisação, antever dificuldades, organizar o trabalho didático, distribuir normalmente o trabalho em relação ao tempo, entre outros fatores para que os objetivos sejam alcançados. Schmitz (1983) acrescenta que o planejamento também é feito para organizar e transformar a ação em unidade, economizar esforços, sistematizar influências e assegurar os resultados, para que as aulas não sejam apenas execução de tarefas mecânicas e sem vida.

Além disso, o planejamento pode permitir a reflexão e análise das melhores maneiras para alcançar os objetivos propostos e obter critérios para possíveis avaliações a fim de aprimorar o processo de ensinoaprendizagem em diferentes sentidos (CABRITO, 2009). Também é preciso ressaltar que, quando a aula não tem a repercussão esperada, não deve provocar sentimento de incapacidade, indignidade e desqualificação, mas a certeza de que era necessário tentar outra via (ALMEIDA; HECKERT; BARROS, 2011).

Lapo e Bueno (2002) apontam o fato de que o grau de satisfação com o trabalho docente pode se relacionar diretamente com os resultados de sua atuação profissional. Portanto, o planejamento pode funcionar como um instrumento extremamente motivador do trabalho docente. Sendo assim, o planejamento deve ser a primeira etapa de todas as atividades, para que o alcance dos objetivos ocorra, e uma ordem progressiva de passos seja seguida para que a ação docente apresente melhores resultados (CRUZ, 1976).

Nesse sentido, a forma como o planejamento pode ser feito é descrito por Schmitz (1983), que elenca quatro passos principais para elaboração de um planejamento. O primeiro seria a sondagem, momento em que é feita a observação dos alunos e do ambiente que eles vivenciam. A sondagem é seguida da elaboração, quando os dados são analisados e há a sistematização teórica com previsão do que se pretende obter, assim traçam-se as linhas gerais de trabalho deixando margem para uma flexibilização futura, pois não é possível prever todas as situações e soluções. O terceiro passo é a execução, quando as atividades passam pelo teste/ 
verificação e podem dar certo ou não. E, por último, a avaliação que deve acompanhar todo o processo e, além disso, verificar se os resultados foram alcançados, sendo essa, uma parte essencial (SACRISTÁN, 1998).

A flexibilização também é citada por Libâneo (1994) que afirma que o ambiente escolar está sempre se reorganizando, sendo necessário haver coerência entre os objetivos gerais, objetivos específicos, conteúdos, métodos e avaliação, adequando-se sempre o que será desenvolvido, com a realidade específica de cada ambiente. Toda a fase de planejamento vai culminar na formulação de um plano de aula, onde estariam presentes: um detalhamento dos itens norteadores da aula; a descrição dos objetivos; descrição das atividades para os alunos; descrição dos materiais e métodos a serem utilizados; além das formas de avaliação. Então, a preparação para as aulas é indispensável que deve resultar em um documento escrito que possa gerar constantes revisões e aprimoramentos na prática docente (LIBÂNEO, 1994).

Conhecer as principais etapas do planejamento é de suma importância, pois através do conhecimento dessas etapas o professor poderá descrever com maior clareza seus objetivos, a forma com que irá desenvolver as atividades, os conteúdos que serão ministrados e como fará o diagnóstico dos resultados obtidos ao longo do processo. Muito se discute sobre as tendências e abordagens pedagógicas da educação física (DARIDO, 2003), mas talvez a última obra no Brasil que tenha discutido aspectos práticos na elaboração de planos de aulas de educação física seja "Introdução à Didática de Educação Física", escrita por Faria Júnior, em 1969.

O presente estudo não se propõe a montar um formulário ideal do tipo "receita de sucesso", no qual os itens do plano de aula vão sendo preenchidos para que, ao final, se tenha um bom plano de aula para educação física. Mais do que isso, é imperativo discutir itens imprescindíveis não apenas para uma organização dos materiais para aulas, mas também para aprimorar o registro e a produção de conhecimento na educação física.

Sendo assim, o objetivo do estudo foi comparar a visão dos discentes iniciantes e concluintes de um curso de Licenciatura em Educação Física sobre a importância dos itens que compõem um plano de aula, bem como discutir esses itens.

\section{MÉTODOS}

O estudo exploratório-descritivo (MARCONI; LAKATOS, 2009) foi desenvolvido com uma amostra de 15 graduandos com possibilidade de conclusão do curso e 15 graduandos dos primeiros dois períodos do curso, de ambos os sexos, regulamente matriculados no curso de licenciatura em educação física de uma universidade federal brasileira. A opção por incluir também os iniciantes ocorreu devido ao interesse de comparar o conhecimento que os alunos têm em relação aos itens que compõe os planos de aulas e a influência do curso de licenciatura em educação física no entendimento da importância de cada item na elaboração do plano de aula.

Os participantes foram convidados a participar do estudo e, após a assinatura do Termo de Consentimento Livre e Esclarecido, receberam uma folha de papel A4, pautada, com uma instrução: "Por favor, monte um plano de aula do conteúdo que você escolher e da maneira que você acredita ser o mais adequado. Não existe plano certo ou errado, o importante é montar o seu plano baseado nas suas convicções. Não forneça informações que permitam te identificar". Os voluntários não tinham restrições de tempo para realizar essa tarefa e posteriormente a lauda era guardada em um envelope pardo. Todo esse procedimento ocorreu na própria universidade.

Em momento posterior os pesquisadores se reuniram para abertura e conferência dos envelopes. Para análise dos planos de aula dois pesquisadores independentes tinham à sua disposição uma lista de itens previamente elencados, dispostos na ordem a seguir: 1ㅇ) Nome da escola; 2ㅇ) Nome do professor; 3ㅇ) Data da aula; 4ㅇ) Ano letivo; 5ㅇ) Número da aula; 6ㅇ) Duração da aula; 7으) Número de alunos na turma; 8이 Idade dos alunos; 9ㅇ) Série; 10ㅇ) Descrição do conteúdo a ser ministrado; 11ㅇ) Definição de um tema para aula; 12ㅇ) Definição de objetivos para aula; 13ㅇ) Descrição detalhada das atividades; 14으) Descrição das variações para uma mesma atividade; 15ㅇ) Previsão de tempo para as atividades; 16ㅇ) Descrição das formas de avaliação; 17으) Descrição dos recursos materiais necessários; 18ㅇ) Descrição do local da aula; 19) Lista de referências bibliográficas; 20ㅇ) Espaço para comentários e reflexões após a aula. 
Para análise estatística dos dados, utilizou-se o teste Qui-Quadrado de independência para testar diferenças entre os alunos iniciantes e os concluintes, sendo adotado nível de significância de 5\%. Foi utilizado o software SPSS v.19.

O estudo foi aprovado pelo Comitê de Ética em Pesquisa com seres humanos da Universidade Federal de Ouro Preto, com o Parecer de n 562.191 e CAAE n ${ }^{\circ} 5598213.0 .0000 .5150$.

\section{RESULTADOS E DISCUSSÃO}

A análise dos planos de aula revelou algo curioso logo nos dois primeiros itens avaliados que apresentaram valores percentuais idênticos e o mesmo padrão de resposta, ou seja, apenas alguns dos concluintes, $17,2 \%$ do total, colocaram em seus planos o "nome da escola" e o "nome do professor". Portanto a maioria dos alunos incluindo todos os iniciantes $(82,8 \%)$ parece não reconhecerem esses dois itens como importantes.

0 "nome da escola" poderia ser considerado um item importante para que o professor recorde, em uma consulta futura, o local para o qual aquela aula foi planejada. O conhecimento do contexto é essencial para dar sentido a um plano de aula (SCHMITZ, 1983; TUBINO, 1996) e, além da consulta do próprio professor, a identificação do local é importante para que outras pessoas consigam visualizar o contexto antes de julgar a pertinência das atividades propostas. Poucos foram os alunos que reconheceram essa importância.

Também houve uma grande porcentagem de alunos que não colocou "nome do professor" em seu plano. Além de dar uma identificação ao autor, colocar o nome do professor permite que esse plano de aula, ou mesmo apenas algumas de suas atividades, sejam corretamente citadas em outros planos de aulas ou em trabalhos acadêmicos. Os itens "nome da escola" e "nome do professor" podem ter sido ignorados também pelo fato de se tratar de planos de aulas hipotéticos.

Nessa mesma tendência, outros itens que apresentaram diferença significativa foram a "descrição do conteúdo a ser ministrado" e a "descrição dos recursos materiais necessários". A "descrição do conteúdo" não foi apresentada por $65,5 \%$ dos graduandos, e, os $34,5 \%$ que apresentaram eram concluintes. Da mesma forma, a "descrição dos recursos materiais necessários" não foi apresentada por $75,9 \%$ dos graduandos e os $24,1 \%$ que apresentaram também eram concluintes.

Como a maioria dos graduandos iniciantes não delineou em seus planos o "conteúdo a ser ministrado" e nem os "recursos materiais necessários", diferentemente do que fizeram os alunos concluintes, cabe a suposição de que a maioria dos concluintes possivelmente passou a perceber a importância desses itens no decorrer do curso e isso se reflete no pequeno percentual desse grupo que não apresentou esses itens.

O "conteúdo a ser ministrado", de acordo com Macedo (1999), é um dos pontos mais relevantes em um plano de aula, pois, apesar da possível omissão na apresentação e discussão de outros itens para sua montagem, os Parâmetros Curriculares Nacionais oferecem um grande número de sugestões de conteúdos a serem trabalhados nas aulas de Educação Física a fim de estimular todas as potências do estudante (BRASIL, 1997; 1998; 2000).

Já a descrição dos "recursos necessários" no plano de aula, pode facilitar ao professor o reconhecimento do que é necessário em sua aula, retirando a necessidade de ler novamente todo o plano para identificar os materiais de que precisa, pois, a falta de tempo do professor também deve ser levada em conta (ALENCAR; FLEITH, 2008). Mas o mais importante em fazer a listagem de materiais é observar a disponibilidade destes na escola em que o plano será desenvolvido, pois existe a realidade de carência de recursos nas escolas (ARRUDA, 2011). Considerando os resultados do presente estudo, alguns dos alunos iniciantes no curso ainda não conseguem notar a necessidade da indicação dos materiais necessários à aula.

Uma resposta completamente oposta aconteceu para os itens "descrição detalhada das atividades" e "definição de objetivos para aula". A "descrição detalhada das atividades" apareceu em $65,5 \%$ dos planos e um fato que chamou a atenção foi que nenhum dos alunos concluintes deixou de apresentar esse item. Já para "definição de objetivos", 62,1\% dos graduandos apresentaram o item, enquanto 37,9\% deixaram de apresentálo e, desse último percentual, apenas um graduando era concluinte.

A maior parte dos graduandos adicionou uma "descrição detalhada das atividades" em seus planos de 
aula e, dos alunos concluintes, nenhum aluno deixou de apresentar esse item. A descrição das atividades é de grande importância como um instrumento para o planejamento do tempo, para o momento da aula e para consulta posterior (LIBÂNEO, 1994). Nesse aspecto o tempo de formação na universidade e a consequente e constante (re) formulação dos saberes pedagógicos, científicos e experienciais que alicerçam a formação (TARDIF, 2014), podem ter gerado a consciência da necessidade desse item.

Foi interessante notar que a maioria dos graduandos incluiu nos planos, os "objetivos da aula". Os objetivos de uma aula devem sempre estar bem balizados, sendo, a grande função do plano de aula, assegurar o cumprimento desses objetivos (SCHIMITZ, 1983). Esses objetivos também devem ter coerência (LIBÂNEO; 1994) atendendo às demandas do contexto já anteriormente estudado e analisado (SCHIMITZ, 1983; TUBINO, 1996). É importante também destacar que esses objetivos devem sempre orientar a avaliação da aula (CABRITO, 2009; SCHIMITZ, 1983).

Além disso, maioria dos alunos iniciantes e concluintes explicitou ser importante descrever algumas variações para as atividades. Libâneo (1994) e Sacristán (1998) acreditam ser essencial deixar, no plano de aula, margem para uma flexibilização das atividades, pois nem sempre é possível prever todas as situações dentro de uma aula, pois o ambiente escolar está sempre se reorganizando, sendo preciso adequar-se sempre o que será desenvolvido em um contexto específico.

A "previsão de tempo para cada atividade" não foi informada por $55,2 \%$ dos graduandos, mas, desse percentual, a maioria é representada pelos iniciantes (68,8\%). Por outro lado, entre os graduandos que apresentaram o item $(44,8 \%)$, a maior porcentagem é formada por concluintes $(76,9 \%)$. O mesmo padrão de resposta foi observado para a "descrição das formas de avaliação", ou seja, não informaram esse item, 62,1\% dos graduandos, sendo que a maioria desse percentual foi representada pelos iniciantes $(66,7 \%)$. Dentre os graduandos que apresentaram o item (37,9\%), a maioria é formada por concluintes $(81,1 \%)$.

Além de variações de atividades, parece que ao longo do curso os graduandos adquiriram a capacidade de perceber a importância da "previsão de tempo para cada atividade", mas esperava-se uma porcentagem menor de concluintes que deixassem de apresentar tal item. Prever o tempo necessário para cada atividade é essencial para que toda a aula e as suas atividades sejam desenvolvidas de forma satisfatória e para que o trabalho seja bem distribuído em relação às possibilidades (CRUZ, 1976), sendo interessante haver a flexibilização desse tempo (SCHIMITZ, 1983) para que os objetivos sejam atingidos.

O item "descrição das formas de avaliação" não foi incluído nos planos da maioria dos discentes. Esse fato é preocupante, pois, segundo Sacristán (1998), a avaliação é o canal pelo qual várias características da aula são analisadas, para compreender condições, limites e potencialidades, na análise de alguns critérios ou pontos de referência, a fim de emitir um julgamento. Portanto, a prática da avaliação é imperativa durante o processo ensino-aprendizagem do educando, sendo assim, o professor que não avalia a sua prática e os seus alunos, está contribuindo para o desperdício do potencial formativo de sua aula, pois é um momento reflexivo de suas próprias ações e das ações dos alunos.

Outro item que tem ligação direta com a avaliação é o "espaço para comentários e reflexões sobre a aula", que não apareceu em nenhum plano de aula. Nesse item é que se analisa o trabalho realizado, colocando à disposição do autor e de futuros leitores, a realidade do que foi vivenciado em aula, os resultados da avaliação e uma análise reflexiva sobre possíveis erros e acertos do professor. A reflexão e análise das aulas verificando se os objetivos propostos foram alcançados e as avaliações foram suficientes são essenciais para a melhora do processo da constante formação do professor (CABRITO, 2009). O conhecimento produzido na Educação Física aumentaria imensamente se as reflexões passassem a fazer parte da rotina dos professores das "quadras de aulas".

Com relação à sessão de "referências bibliográficas", nenhum dos alunos se lembrou de adicioná-la ao plano, fato preocupante, pois, há muitos livros que discutem aspectos teóricos que podem ser relacionados com a prática e, ao construir um plano de aula, é preciso se basear em alguns desses livros que discutem os conteúdos, as atividades, as concepções, as metodologias e outros fatores (BARROSO; DARIDO, 2009; 2010; BRASIL, 1997; 1998; 2000; COLL et al., 2000; LIBÂNEO, 1994; ZABALA, 1998). O fato pode ter ocorrido pela situação de escrita dos planos, sem consulta, o que traz uma necessidade de discutir sobre novos estudos em que haja a possibilidade do plano ser construído mediante consulta dos participantes a diferentes fontes. Essa é uma limitação do presente estudo. 
A "data" e o "número da aula" não foram considerados aspectos importantes pelos alunos iniciantes, mas esses itens são necessários na contextualização das atividades desenvolvidas, além de contribuir na organização das atividades e acenar para a impossibilidade de aplicabilidade de um plano pensado para determinado período do ano, onde o sol pode causar grande desconforto aos alunos. A exposição às intempéries climáticas deve sempre ser considerada na construção dos planos de aula e das variações de atividades (ARRUDA, 2011). Assim esses itens poderiam facilitar a interpretação do autor do plano ou mesmo de outros leitores sobre a possibilidade de reaplicar esse plano considerando uma sequência de aulas e mesmo o período do ano, se inverno ou verão.

O item "número de alunos na turma" apresentou um resultado não esperado pelos pesquisadores, pois alguns dos concluintes não identificaram o item como essencial dentro de um plano. O número de alunos, ou uma média de alunos, é fundamental na construção do plano de aula para que não haja nenhum aluno excluído de uma atividade ou poucos alunos para participarem de outra determinada atividade. Também é importante para determinar o espaço e os materiais necessários, para evitar improvisações que podem prejudicar a aprendizagem dos alunos.

Outro aspecto importante também negligenciado nos planos de aula é o espaço para comentários e reflexões após a aula. A produção do conhecimento em Educação Física aumentaria muito se esse tipo de informação passasse a fazer parte da rotina dos professores de educação física. Talvez os professores em atuação também não façam essa reflexão sobre sua prática, fato que abriria espaço para novas pesquisas e discussões. A ideia de um repositório on-line de planos de aulas nos quais constassem essas reflexões finais vem sendo discutida pelos autores do presente trabalho, e seria implementado pelo menos para as disciplinas de estágio supervisionado da universidade. O que já ficou consolidado na discussão é o fato de que todos os planos que forem colocados nesse repositório teriam que atender a pelo menos duas exigências iniciais: a) terem sido aplicados em situações de aula; b) o autor do plano deveria obviamente realizar uma reflexão de sua prática após a aula. A forma como o próprio autor do plano realizaria esse envio on-line do seu plano de aula já foi discutido, e a necessidade de um formulário com informações mínimas sobre a aula pode ter sido o gatilho para todo o estudo e escolha dos itens que os autores do presente trabalho apresentaram aqui para discussão. A cobrança dos itens aqui apresentados já ocorre nas disciplinas de estágio supervisionado, faltando agora essa plataforma de envio e outros detalhes como a autorização dos autores dos planos para divulgação desses planos de aulas na internet.

Os resultados do presente estudo mostram que a descrição das atividades foi o único item que todos aos alunos perceberam como importante e apresentaram em seus planos. Os dados também evidenciam que existe uma necessidade urgente de valorização dos autores da área da educação física, pois nem mesmo alunos concluintes adicionaram uma sessão de referências bibliográficas ou lembraram o nome de autores e livros para indicação, mesmo que de maneira precária e incompleta.

Ainda sobre as publicações considerando a temática abordada no artigo, também existe uma grande necessidade de colaborações originais. Faltam na literatura artigos recentes que permitam a discussão dos dados aqui levantados. Não foram encontrados trabalhos além daqueles que são citados no presente estudo e a grande limitação desse artigo se caracterizou por essa carência de referências no formato de artigos, teses, dissertações e trabalhos de conclusão de curso para corroborar ou contrapor tudo o que foi aqui discutido. Olhando por outro prisma, talvez faltasse uma provocação que gerasse o estopim para a discussão dos itens que devem, ou deveriam compor um plano de aula para Educação Física e dessa forma o presente artigo passa a colaborar com a produção de conhecimento da área mostrando essa necessidade.

\section{CONSIDERAÇÕES FINAIS}

A proposta do estudo foi identificar e discutir itens que alunos de um curso de licenciatura em educação física (iniciantes e concluintes) julgam importantes para elaboração de planos de aulas. Diante dos resultados obtidos, e considerando as limitações do estudo, é possível afirmar que os discentes compreendem a descrição das atividades em um plano de aula como o item imprescindível e talvez o mais importante, sendo todos os demais itens, em alguma medida, negligenciados.

Além disso, há uma carência de referências originais que abordem a temática do presente trabalho, fato que prejudicou a discussão dos dados e apontou para necessidade de novos estudos. 


\section{REFERÊNCIAS}

ALENCAR, E. M. L. S.; FLEITH, D. S. Barreiras à promoção da criatividade no ensino fundamental. Psicologia: Teoria e Pesquisa, Brasília, v. 24, n. 1, p. 59-65, 2008.

ALMEIDA, U. R.; HECKERT, A. L. C.; BARROS, M. E. B. Nas trilhas da atividade: análise da relação saúde-trabalho de uma professora de educação física escolar. Trabalho Educação e Saúde, Rio de Janeiro, v. 9, supl. 1, p. 245-63, 2011.

ARRUDA, M. C. C. Escola pública e pobreza no Brasil: a ampliação para menos. Cadernos de Pesquisa, São Paulo, v. 41, n. 143, p. 664-6, 2011.

BARROSO, A.; DARIDO, S. C. A pedagogia do esporte e as dimensões dos conteúdos: conceitual, procedimental e atitudinal. Revista da Educação Física/UEM, Maringá, v. 20, n. 2, p. 281-9, 2009.

BARROSO, A.; DARIDO, S. C. Voleibol escolar: uma proposta de ensino nas dimensões conceitual, procedimental e atitudinal do conteúdo. Revista Brasileira de Educação Física e Esporte, São Paulo, v. 24, n. 2, p. 179-94, 2010.

BRASIL. Ministério da Educação. Secretaria de Educação Média e Tecnológica. Parâmetros Curriculares Nacionais (Ensino Médio). Brasília: MEC, 2000.

BRASIL. Secretaria de Educação Fundamental. Parâmetros curriculares nacionais: Educação Física. Secretaria de Educação Fundamental. Brasília: MEC/SEF, 1998.

BRASIL. Secretaria de Educação Fundamental. Parâmetros curriculares nacionais: Educação Física. Secretaria de Educação Fundamental - Brasília: MEC/SEF, 1997.

CABRITO, B. G. Avaliar a qualidade em educação: avaliar o quê? Avaliar como? Avaliar para quê? Caderno CEDES, Campinas, v. 29, n. 78, p. 178-200, 2009.

COLL, C.; MARTIN, E.; MAURI, T.; MIRAS, M.; ONRUBIA, J.; SOLÉ, I.; ZABALA, A. Os conteúdos na reforma: ensino e aprendizagem de conceitos, procedimentos e atitudes. Porto Alegre: Artmed, 2000.

CRUZ, C. E. O planejamento das atividades didáticas. In: CASTRO, A. D. Didática da escola média: teoria e pratica. São Paulo: Edibell, 1976.

DARIDO, S. C. Educação física na escola questões e reflexões. Rio de Janeiro: Guanabara Koogan, 2003.

FARIA JÚNIOR, A. G. Introdução à didática de educação física. Brasília: Divisão de Educação Física Ministério da Educação e Cultura, 1969.

LAPO, F. R.; BUENO, B. O. O abandono do magistério: vínculos e rupturas com trabalho docente. Psicologia USP, São Paulo, v. 13, n. 2, p. 243-76, 2002.

LIBÂNEO, J. C. Didática. São Paulo: Editora Cortez, 1994.

MACEDO, E. F. Parâmetros curriculares nacionais: a falácia dos temas transversais. In: MOREIRA, A. F. B. (Org.). Currículo, políticas e práticas. Campinas: Papirus, 1999

MARCONI, M. A; LAKATOS, E. M. Técnicas de pesquisa: planejamento e execução de pesquisas; amostragens e técnicas de pesquisa; elaboração análise e interpretação de dados. São Paulo: Atlas, 2009.

NASCIMENTO, A. E.; SILVA, J. V.; SANTOS, F. A. Aulas de educação física escolar: entre o planejamento e a improvisação. In: XVIII Congresso Brasileiro de Ciências do Esporte (CONBRACE) e V Congresso Internacional de Ciências do Esporte (CONICE). Anais... Brasília, 2013. p. 35-46.

NOGUEIRA, N. O. A apropriação do conhecimento escolar: relações com o currículo numa escola de ensino fundamental. 2004. 191f. Dissertação (Mestrado em Educação) - Pontifícia Universidade Católica de Minas Gerais, Belo Horizonte, 2004.

SACRISTÁN, J. G. A avaliação no ensino. In: SACRISTÁN, J. G.; PÉRES GÓMES, A. I. Compreender e transformar o ensino. 4.ed. Porto Alegre: Artmed, 1998.

SCHMITZ, E. F. Planejamento educacional. In: SCHMITZ, E. F. Didática moderna: fundamentos. Rio de Janeiro: LTC, 1983

SOARES, C. L.; TAFFAREL, C.; VARJAL, E.; CASTELLANI FILHO, L.; ESCOBAR, M. O.; BRACHT, V. Metodologia do ensino de educação física. São Paulo: Cortez, 1992. 
TARDIF, M. Saberes docentes e formação profissional. 17.ed. Petrópolis: Vozes, 2014.

TUBINO, M. J. G. O esporte no Brasil: do período colonial aos nossos dias. São Paulo: Ibrasa, 1996.

UNESCO. O perfil dos professores brasileiros: o que fazem, o que pensam, o que almejam. São Paulo: Moderna, 2004.

ZABALA, A. A prática educativa: como ensinar. Porto Alegre: Artmed, 1998.

Autor correspondente: Emerson Cruz de Oliveira

E-mail:emerson@cedufop.ufop.br
Recebido: 7 de setembro de 2017.

Aceito: 31 de janeiro de 2018. 